\title{
Mycobacterium avium Subspecies Paratuberculosis and Crohn's Regional lleitis: How Strong is Association?
}

\author{
Sarman Singh, Krishnamoorthy Gopinath ${ }^{1}$
}

Department of Laboratory Medicine, Division of Clinical Microbiology, All India Institute of Medical Sciences, New Delhi, India, ${ }^{1} \mathrm{MRC} / \mathrm{NHLS} /$ WITS Molecular Mycobacteriology Research Unit, University of the Witwatersrand and the National Health Laboratory Service, Johannesburg, South Africa

Address for correspondence: Prof. Sarman Singh, E-mail: sarman_singh@yahoo.com

\section{ABSTRACT}

Mycobacterium avium subsp. paratuberculosis (MAP) is a well-established etiological agent of Johne's disease in animals. In humans, similar clinical condition, first described by Crohn as regional ileitis in 1932, now known as Crohn's diseases (CD), has also been associated with this mycobacterial species. However, there are two schools of thoughts, one favoring MAP as its etiological agent while the second considers it as an immune-inflammatory condition triggered by an external factor. Onset of $C D$ requires a series of events including predisposition of certain inherited genetic traits, associated environmental stimuli, and immune-inflammatory response. A combination of these factors probably leads to this disease. Recently, some human genes have also been identified which regulate ability to respond appropriately to the external factors. Added to these factors are concerns about the selection of clinical specimens and poor adherence to laboratory quality controls. The literature is full of contradictory findings, but there a lack of uniformity in the materials and methods used by many of these researchers. In this review, we provide our perspective under above circumstances and give our point of view which may open a platform for debate regarding the MAP as the etiological agent of human CD.

Keywords: Crohn's disease, IS900, Johne's disease, Mycobacterium avium subsp. paratuberculosis, mycobacterium, paratuberculosis

\section{INTRODUCTION}

rohn's disease $(\mathrm{CD})$ in humans was described by Crohn et al., ${ }^{[1]}$ as a chronic inflammatory reaction of the intestines, characterized by protein losing enteropathy, malabsorption, and steatorrhea. Discrete and/or serpiginous ulcers and a cobblestone appearance are hallmarks of this disease. ${ }^{[2]}$ Histologically, there is mucosal erosion and neutrophil infiltrates are seen within crypts and crypt abscesses are formed that progress to transmural lymphogranulomatous enteritis. A similar entity in animals later on known as Johne's disease (JD) manifests itself as a chronic granulomatous infection of the intestine, resulting in progressive weight loss, emaciation, cachexia in the

\begin{tabular}{|c|c|}
\hline \multicolumn{2}{|c|}{ Access this article online } \\
\hline $\begin{array}{c}\text { Quick Response Code: } \\
\square \square\end{array}$ & $\begin{array}{l}\text { Website: } \\
\text { www.jlponline.org }\end{array}$ \\
\hline$m^{2} \mathrm{~s}^{4}$ & $\begin{array}{l}\text { DOI: } \\
10.4103 / 0974-2727.86836\end{array}$ \\
\hline
\end{tabular}

affected animal which can lead to death. ${ }^{[3-5]}$ Due to the clinical symptoms of CD closely mimicking those found in animals with JD, it was proposed almost 90 years ago that the two diseases shared the same etiology. ${ }^{[6]}$

Mycobacterium avium subsp. paratuberculosis (MAP) is a well-established etiological agent of JD. Johne and Frothingham initially reported the disease in Germany in 1894; however, it was not until 1910 that Trowt successfully fulfilled Koch's postulates by growing MAP in the laboratory and reproducing the disease in experimentally infected cattle. ${ }^{[7]}$ In animals, the mode of transmission of MAP is usually through the fecal-oral route and occurs either by ingesting the organism through contaminated milk or food products or by accidental ingestion of the microorganism from contaminated surfaces. ${ }^{[8]}$ Subclinically or clinically infected animals shed MAP in feces and milk, enabling dissemination to susceptible calves, the environment, and in retail milk. $\cdot^{[9-11]}$ Although MAP is considered an obligatory parasite, it can survive in the environment and can be carried from livestock and wildlife 
'reservoirs' into drinking water systems and thus expose human populations ${ }^{[12]}$ [Figure 1]. The infection is often restricted to the intestine, but the bacteria can spread from the primary site of infection in the intestine to liver, spleen, kidney, uterus, and mammaries through hematogenous or lymphatic routes via monocytes and can be isolated from these organs. ${ }^{[13]}$

\section{LABORATORY DIAGNOSIS OF CROHN'S DISEASE}

The diagnosis of $\mathrm{CD}$ is made only on the basis of clinical suspicion and is a matter of clinical acumen. However, since there is no pathogenomic feature of the disease, only pathological findings can confirm the entity. Nonetheless, isolation of MAP from the intestinal tissue of CD patients in some laboratories led to debate that it may be the pathogenic for humans and a possible etiological agent of CD. However, this issue still remains controversial having reports both in favor as well against this theory. ${ }^{[0-11]}$ A systematic review and meta-analysis of the various published reports reveals that the association of MAP with CD seems to be specific, but its role in the etiology of $\mathrm{CD}$ remains to be established ${ }^{[14]}$ [Figure 1].

MAP is an intracellular pathogen that persists in the cell wall deficient form; thereby escapes clearance by the host immune system. ${ }^{[15,16]}$ MAP can switch to a tough Ziehl Neelson negative form in which it is invisible by ordinary light microscopy in infected tissues of human and requires exogenous mycobactin an iron-transport protein for in vitro growth but usually results in very slow growth. These inherent problems limit the chance of isolating them and strains of bovine or human origin may require months or years of incubation before their growth becomes visible,

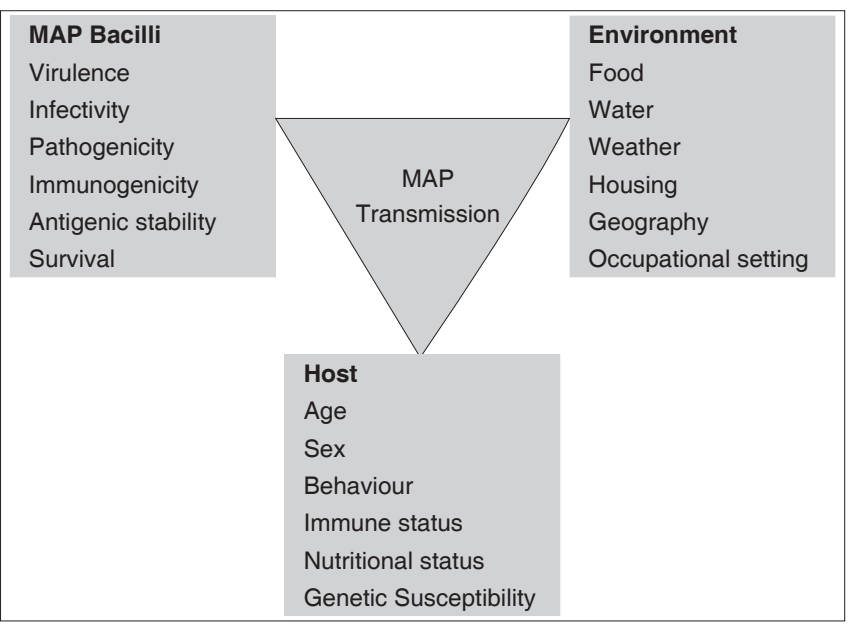

Figure 1: Schematic illustration of different modes of transmission and factors determining the pathogenicity of $M$. avium subsp. Paratuberculosis whereas, serological tests lack specificity because of ubiquitous nature of the organism. These tests also have low sensitivity because the seroconversion occurs relatively late during the course of the disease. ${ }^{[17]}$ Polymerase chain reaction (PCR) amplification of IS900 gene of MAP from clinical specimen is a reliable alternative modality ${ }^{[18]}$ to culture and serological assays for the confirmation of MAP infection in the specific tissue. However, every test system has its own limitations and we would like to highlight these in the following paragraphs.

\section{PROBLEMS IN DIAGNOSTIC METHODS}

Culture isolation of the suspected mycobacterium except Mycobacterium leprae remains the gold standard to claim as etiology of any mycobacterial disease. Using Herrold's egg yolk agar with mycobactin J (HEYA) faecal culture and/or BACTEC MGIT 960, the MAP is usually demonstrated from the samples collected from animals suffering from JD. ${ }^{[19,20]}$ Interestingly in the case of MAP, its genotypically diverse subtype populations behave differently in the liquid culture method (BACTEC MGIT 960) than the solid culture method. A variety of subtypes are observed in the liquid cultures obtained from the same fecal samples which suggests that culture methods could provide a "microbiological" bias and lead to a discrepant results. ${ }^{[21]}$ The shedding of MAP of JD is often pluribacillary as compared to human genotypes of MAP, which is usually paucibacillary. ${ }^{[2]}$ The trend is quite similar to the form of CNS and pleural tuberculosis, where acid fast bacilli (AFB) smears positivity is only $10-20 \%$ and poses a diagnostic challenge. ${ }^{[23]}$ In a study from India, one group of authors have claimed a positivity rate of $37.5 \%$ (3/8) by smear, $80 \%(4 / 5)$ by culture, and $100 \%(5 / 5)$ by enzymelinked immunosorbent assay (ELISA) in the CD patients. Interestingly these authors also reported that $75 \% \mathrm{JD}$ animal handlers and 38\% healthy persons positive for antiMAP antibodies detected by ELISA. ${ }^{[24]}$ The major bias in the study was that the authors did not rule out co-infection of other mycobacteria or other infectious and noninfectious etiologies of colitis in their patients. It is very much possible that the fecal samples which were positive for acid fast bacilli were environmental mycobacteria. Some authors have reported high sensitivity of PCR on human colonic tissues ${ }^{[18,25-27]}$ and in paraffin-embedded tissue sections ${ }^{[28]}$ but these findings have not been reproducible.

\section{WHICH SAMPLE IS APPROPRIATE AND IDEAL?}

Quite often, there is a dilemma over establishing the link with MAP as infectious etiology of CD and one is not 
sure about the most appropriate clinical specimen from the non-sterile inflicted sites. Mere isolation even in pure culture from feces or intestinal biopsy material may not be indicative of disease causation. Pierce ${ }^{[29]}$ suggested that if the MAP are demonstrated by direct microscopy in blood vessels, lymph vessels (lymphatics), and lymph nodes in the mesentery of affected bowel wall segments, mesentery itself, i.e., the adipocytes that fill the mesentery and in the walls of fistulae, the causal role of MAP in $\mathrm{CD}$ will be confirmed. However, till it happens and confusion goes on, a few studies claimed to isolate MAP from patients of $\mathrm{CD}$ as well as from healthy population. A study from India, cultured MAP bacilli from fecal specimens from five $(62.5 \%)$ of the eight persons involved in animal husbandry practices and 6 of $22(27.2 \%)$ healthy humans. ${ }^{[24]}$ In another study carried out by Scanu et al[20] MAP was detected in 15 of $20(75 \%)$ patients with irritable bowel syndrome, 3 of 20 (15\%) healthy controls, and 20 of $23(87 \%)$ CD patients. However, Sechi et al. ${ }^{[16]}$ reported that $63.3 \%$ of the CD patients and $10.3 \%$ of the control cases were MAP culture positive. MAP has been cultured in a significantly higher percentage of bowel-pinch biopsies from CD patients $(42 \%)$ vis-a-vis from controls $(9 \%) .{ }^{[19]}$ With the PCR method, the positivity rate has increased up to $83.3 \%$ in CD patients, but no difference was observed in control cases. ${ }^{[16]}$ By taking together of all these findings, it is quite compelling to conclude that MAP occurrence in healthy individuals may be mere colonization, and may not have causal role. Nevertheless, a significant association is observed between the disease and the consumption of hand-made cheese ${ }^{[20]}$ dairy products and raw water. ${ }^{[12]}$ All these sources have yielded MAP positive cultures. Albeit, isolation of MAP bacilli or their DNA from stool specimen of the CD patients may not be conclusive evidence to establish causal etiology of the MAP in CD.

This uncertainty is not restricted to nonsterile specimens, but also with sterile specimens such as blood. Live MAP or its DNA is reported to be detected from blood of CD patients and showed mixed results. ${ }^{[15,30,31]}$ Juste et al. ${ }^{[30]}$ also detected the MAP DNA in blood of healthy individuals, and when the results compared with IBD patients it was found that $47 \%(47 / 100)$ healthy controls and 16\% (40/246) IBD patients were positive for IS900 DNA when amplified by a nested PCR protocol. These findings further indicate that MAP has no direct causal role in CD. The same group of workers ${ }^{[32]}$ reproduced the similar results and reported significant correlation with the elevated IFN $\gamma$ (uninduced with MAP antigen) levels in controls as compared to IBD patients, indicating that healthy individuals (but not IBD patients) have a significantly stronger cellular immune response that might be able to control the infection in these individuals. It seems to be a good hypothesis, which needs to be proven. These "selection biases" need to be avoided to establish that MAP is the causative agent of $\mathrm{CD}$, only if appropriate healthy as well as diseases controls are included in these studies with detailed clinical and laboratory details. We feel that good epidemiological studies with extensive details of demography, living style, possible contaminating source of MAP (food and water), MAP infection/colonization status of their family members (including genetic makeup) or population who have equal probability of access to the same habitat are urgently needed. The investigators should not only focus on MAP in these patients but extensive collaborative studies where other possible agents and factors are also investigated in a comprehensive manner. The resulting data will be helpful to understand the etiology, pathogenesis and possible risk factors that favor the disease/infection/colonization only in few individuals and what prophylactic measures can be adopted.

\section{GOOD LABORATORY PRACTICES AND QUALITY ASSURANCE}

The results of the studies proving the infectious etiology of $\mathrm{CD}$ will be informative only with the adherence to the stringent quality control procedure by processing the specimen in Level II Bio-safety hoods for DNA extraction and separate uniforms, rooms, pipettes, and thermal cyclers for the PCR amplification. Special attention must be given to purity of water used for preparing buffers and other reagents, especially in tropical countries. Even though many studies have shown very high culture and PCR positivity from diseased and un-diseased persons, but studies with more stringent methods did not support these findings. Ellingson et al. ${ }^{[13]}$ using a cross-species and cross-disease samples (CD and JD) compared multiple detection techniques [histology, immunocytochemistry, and IS900 polymerase chain reaction], and found that the IS900 sequence was demonstrable in all samples of confirmed positive JD tissue but none of the 35 patients of $\mathrm{CD}, 36$ patients of ulcerative colitis, and 21 patients of diverticular disease. To address the concern of the low detection rate by PCR, the presence of PCR inhibitors must be checked by amplifying any of the known human housekeeping genes like $\beta$-actin, NADPH, or $\beta$-globulin. ${ }^{[33]}$ Whereas, the chances of cross contamination are difficult to control in a laboratory where primarily samples of animal origin are being handled along with human samples. ${ }^{[4]}$ We feel that findings from such laboratories should be interpreted with extreme care. The studies' results from such laboratories must ensure about the prevention of cross contamination 
by storing the specimens and processing them in a dedicated place, which were physically distant from each other. Other important factors such as details about the collection and transportation of specimens, quality and quantity of specimens must be considered. The knowledge of pathophysiology, different stage(s) of their infection and corresponding bacilli load is very scarce and testing the samples collected during the early stages of infection may not be useful. Therefore, minimum guidelines and necessary criteria need to be made regarding collection of specimens, performance of tests, and interpretation of their results in both diseased and control cases to demonstrate the etiology of MAP.

\section{Host factors}

It is postulated that human CD may sometime prove to be an immunity-mediated condition where some gene might be identified that increase susceptibility of the gut mucosa to general bacterial flora of the gastrointestinal tract. Recently, a gene known as CARD15/NOD2 situated within the IBD1 region of chromosome 16q12 has been identified which is associated with susceptibility to $\mathrm{CD} \cdot{ }^{[34,35]}$ The $C A R D 15$ has been proposed to be an intracellular receptor for bacterial components in the monocytes. Three main mutations of $C A R D 15$ have been found in patients with $\mathrm{CD}$, but not in patients with ulcerative colitis. ${ }^{[34,35]}$ Others have found that smoking habit aggravates the course of $\mathrm{CD}$ and promotes formation of fistulas, strictures, and other complications. ${ }^{[36]}$

There is counter evidence which does not support MAP etiology of CD. These include host conditions, such as HIV infection, ${ }^{[37]}$ organ transplantation or patients with immunosuppressive treatment, or Type I diabetes mellitus, ${ }^{[38]}$ which otherwise favor the multiplication of MAP but surprisingly, incidence of MAP has not been found higher in these populations. On the contrary, immunosuppressive therapy is found to be beneficial to the CD patients. ${ }^{[39]}$ It is quite possible, though, that in HIV-TB endemic settings, Mycobacterium tuberculosis grows comparatively faster than MAP and may overgrow the $\mathrm{MAP},{ }^{[40]}$ and thus many diagnostic laboratories might be missing the co-infections of $M$. tuberculosis and MAP. Nonetheless, one has to be cautious in reporting high MAP-PCR positivity in AIDS patients, which is often a false positive result.

\section{STRAIN VARIATIONS IN MAP}

More than 30 strains of MAP have been identified using methods such as restriction endonuclease analysis, IS900 RFLP, and PFGE . ${ }^{[41-45]}$ Typing of over a thousand MAP isolates obtained from all over the world has demonstrated differences between ovine strains (S-type or type I) and bovine strains (C-type or type II), suggesting an adaptation to their respective preferred hosts. Although phenotypic and genotypic differences are found between ovine strains and bovine strains, they nonetheless share substantial intra-species commonality. The major differences are interspecies [Table 1]. Studies in Iceland and the Netherlands have shown that sheep strains of MAP can infect cattle, and cattle strains of MAP can give rise to long-standing subclinical infection in sheep grazing the same pastures. ${ }^{[46]}$ Bovine strains, however, have a much broader host range. IS900 RFLP typing of MAP isolates from humans with CD has so far demonstrated that they all belong to the cattle C-type/type II background. ${ }^{[46]}$ A unique 12-bp tandem repeat sequence present in sheep strains is absent from bovine strains, making these strains distinguishable by specific PCR. ${ }^{[41,46]}$ The use of representational difference analysis has further identified an $11 \mathrm{bp}$ fragment present in sheep strains which is absent from bovine strains. Differences in MAP strains from cattle and sheep have been demonstrated between Argentina and Europe, ${ }^{[4]}$ and between Australia and Iceland. ${ }^{[46]}$ Typing of IS1311 polymorphisms from MAP isolates obtained from nine

\begin{tabular}{|c|c|c|c|c|c|c|}
\hline Property & MAP & M. avium & M. tuberculosis & M. bovis & M. leprae & M. smegmatis \\
\hline Genome size, bp & $4,829,781$ & $5,475,738$ & $4,411,532$ & $4,345,492$ & $3,268,203$ & $6,988,209$ \\
\hline GC content, $\%$ & 69.30 & 68.99 & 65.61 & 65.63 & 57.79 & 67.40 \\
\hline Protein coding, $\%$ & 91.30 & NA & 90.80 & 90.59 & 49.50 & 92.42 \\
\hline ORFs & 4,350 & NA & 3,959 & 3,953 & 1,604 & 6,897 \\
\hline Gene density, bp per gene & 1,112 & NA & 1,114 & 1,099 & 2,037 & 1,013 \\
\hline Average gene length, bp & 1,015 & NA & 1,012 & 995 & 1,011 & 936 \\
\hline tRNAs & 45 & 45 & 45 & 45 & 45 & 47 \\
\hline rRNA operon & 1 & 1 & 1 & 1 & 1 & 2 \\
\hline$A B C$ transporters $^{\mathrm{a}}$ & 60 & - & 39 & 42 & 24 & - \\
\hline
\end{tabular}

annublished data. 
bison in Montana, USA showed consistent variation at base position 223 compared with 13 C-type isolates from cattle and goats in the other parts of the United States. Taken together, the findings are consistent with predictable geographical differences in MAP isolates between continents and different regions. Diversification of MAP strains is a continuing dynamic process and human MAP strains and type-specific features can be expected.

RFLP and PFGE are methods which limit the typing of MAP to those strains which can be cultured. Given the very slow growth, and in some cases unculturable nature of these organisms, PCR-based typing procedures for these difficult pathogens are highly desirable. PCR typing of M. tuberculosis based upon mycobacterial interspersed repetitive units ${ }^{[46]}$ has been adapted for MAP. PCR typing based upon six mycobacterial interspersed repetitive units loci, distinguishes MAP from other Mycobacterium avium complex (MAC) [Table 1]. This observation may be useful in a clinical settings if the isolates of MAP in liquid cultures from the clinical sample are pure or mixed with other MAC organisms. ${ }^{[48]}$

\section{CONCLUSION}

Crohn's disease (CD) is a devastating inflammatory illness in search of a cause and a cure. It needs some trigger such as microorganisms. It is suspected that some individuals have genetic inability to interact appropriately with certain bacteria or bacterial products and that might cause increased vulnerability for $\mathrm{CD}$. The bacterial suspects at the moment include a Mycobacterium species, specially $M$. avium subsp. paratuberculosis and some strains of Escherichia coli. The possibility of more than one infectious cause cannot be ruled out due to the presence of huge normal flora in the gut. Researchers have reported that people with CD have 7:1 odds of having a documented presence of MAP in blood or gut tissues than those who do not have CD. However, the critical issue is whether MAP causes CD or as only incidentally present in tissue not participating in the disease process. MAP is ubiquitous in environment and persists in contaminated soil and water. MAP has a cell wall that contains muramyl dipeptide (MDP). Some people have mutations in their genes, like NOD2, which regulates ability of the host to respond appropriately to MDP. Hence, persons having gene mutations in NOD2 may be more vulnerable. Circumstantially, these observations appear to make a compelling case of involving MAP in CD. On the other hand, several clinical trials with existing anti-tubercular drugs have either failed completely or produced partial cure. Also, while the site of infection and tissue pathologies of MAP in animals can be assessed at necropsy, there is enough dissimilarities between digestive processes of ruminants and humans that this information may not necessarily translate in humans. Further, recent studies have shown that immunosuppressive drugs such as cyclosporine $\mathrm{A}$, rapamycin and tacrolimus have shown encouraging results. These findings put a big question mark on MAP etiology of the CD. It is proposed that with the available genomic data of MAP, sensitive and specific diagnostics will be developed. We can also expect that specific pathways or proteins involved in successful establishment of MAP in diverse inanimate environmental sources, such as water, milk and soil, and diverse biological conditions, e.g. animals and human guts, could be identified. It is very much possible that combination of several factors is found in near future which facilitate this disease.

\section{REFERENCES}

1. Crohn BB, Ginzburg L, Oppenheimer GD. Regional ileitis; a pathologic and clinical entity. JAMA 1932;99:1323-9.

2. Hamilton SR, Morson BC. Crohn's disease. Part 1: Pathology. In: Haubrich WS, Schaffner F, Berk JE, Bockus HL, editors. Bockus gastroenterology. Vol. 2. Philadelphia: W.B. Saunders; 1995. p. 1398-409.

3. Buergelt CD, Duncan JR. Age and milk production data of cattle culled from a dairy herd with paratuberculosis. J Am Vet Med Assoc 1978;173:478-80.

4. Benedictus G, Dijkhuizen AA, Stelwagen J. Economic losses due to paratuberculosis in dairy cattle. Vet Rec 1987;121:142-6.

5. Clarke CJ. The pathology and pathogenesis of paratuberculosis in ruminants and other species. J Comp Pathol 1997;116:217-61.

6. Dalziel TK. Chronic intestinal enteritis. Br Med J 1913;21068-70.

7. Chiodini RJ, Van Kruiningen HJ, Merkal RS. Ruminant paratuberculosis Johne's disease: The current status and future prospects. Cornell Vet 1984;74:218-62.

8. Cocito C, Gilot P, Coene M, de Kesel M, Poupart P, Vannuffel P. Paratuberculosis. Clin Microbiol Rev 1994;7:328-45.

9. Cellier C, De Beenhouwer H, Berger A, Penna C, Carbonnel F, Parc R, et al. Mycobacterium paratuberculosis and Mycobacterium avium subsp. silvaticum DNA cannot be detected by PCR in Crohn's disease tissue. Gastroenterol Clin Biol 1998;22:675-8.

10. Chiba M, Fukushima T, Horie Y, Iizuka M, Masamune O. No Mycobacterium paratuberculosis detected in intestinal tissue, including Peyer's patches and lymph follicles, of Crohn's disease. J Gastroenterol 1998;33:482-7.

11. Clarkston WK, Presti ME, Petersen PF, Zachary PE Jr, Fan WX, Leonardi CL, et al. Role of Mycobacterium paratuberculosis in Crohn's disease: A prospective, controlled study using polymerase chain reaction. Dis Colon Rectum 1998;41:195-9.

12. Sung N, Collins MT. Variation in resistance of Mycobacterium paratuberculosis to acid environments as a function of culture medium. Appl Environ Microbiol 2003;69:6833-40.

13. Ellingson JLE, Cheville JC, Brees D, Miller JM, Cheville NF. Absence of Mycobacterium avium subspecies paratuberculosis components from Crohn's disease intestinal biopsy tissues. Clin Med Res 2003;1:217-26.

14. Feller M, Huwiler K, Stephan R, Altpeter E, Shang A, Furrer H, et al. Mycobacterium avium subspecies paratuberculosis and Crohn's disease: A systematic review and meta-analysis. Lancet Infect Dis 2007;7:607-13.

15. Naser SA, Ghobrial G, Romero C, Valentine JF. Culture of Mycobacterium avium subspecies paratuberculosis from the blood of patients with Crohn's disease. Lancet 2004;364:1039-44.

16. Sechi LA, Scanu AM, Molicotti P, Cannas S, Mura M, Dettori G, et al. 


\section{Singh and Gopinath: Role of MAP in Crohn's disease}

Detection and isolation of Mycobacterium avium subspecies paratuberculosis from intestinal mucosal biopsies of patients with and without Crohn's disease in Sardinia. Am J Gastroenterol 2005;100:1529-36.

17. Clarke CJ, Patterson IA, Armstrong KE, Low JC. Comparison of the absorbed ELISA and agar gel immunodiffusion test with clinicopathological findings in ovine clinical paratuberculosis. Vet Rec 1996;139:618-21.

18. Sanderson JD, Moss MT, Tizard ML, Hermon-Taylor J. Mycobacterium paratuberculosis DNA in Crohn's disease tissue. Gut 1992;33:890-96.

19. Bull TJ, McMinn EJ, Sidi-Boumedine K, Skull A, Durkin D, Neild P, et al. Detection and verification of Mycobacterium avium subsp. paratuberculosis in fresh ileocolonic mucosal biopsy specimens from individuals with and without Crohn's disease. J Clin Microbiol 2003;41:2915-23.

20. Scanu AM, Bull TJ, Cannas S, Sanderson JD, Sechi LA, Dettori G, et al. Mycobacterium avium subspecies paratuberculosis infection in cases of irritable bowel syndrome and comparison with Crohn's disease and Johne's disease: Common neural and immune pathogenicities. J Clin Microbiol 2007;45:3883-90.

21. Cernicchiaro N, Wells SJ, Janagama H, Sreevatsan S. Influence of type of culture medium on characterization of Mycobacterium avium subsp. paratuberculosis subtypes. J Clin Microbiol 2008;46:145-9.

22. Vary PH, Andersen PR, Green E, Hermon-Taylor J, McFadden JJ. Use of highly specific DNA probes and the polymerase chain reaction to detect Mycobacterium paratuberculosis in Johne's disease. J Clin Microbiol 1990;28:933-7.

23. Thwaites GE, Simmons CP, Than Ha Quyen N, Thi Hong Chau T, Phuong Mai P, Thi Dung N, et al. Pathophysiology and prognosis in vietnamese adults with tuberculous meningitis. J Infect Dis 2003;188:1105-15.

24. Singh AV, Singh SV, Makharia GK, Singh PK, Sohal JS. Presence and characterization of Mycobacterium avium subspecies paratuberculosis from clinical and suspected cases of Crohn's disease and in the healthy human population in India. Int J Infect Dis 2008;12:190-7.

25. Moss MT, Sanderson JD, Tizard ML, Hermon-Taylor J, el-Zaatari FA, Markesich DC, et al. Polymerase chain reaction detection of Mycobacterium paratuberculosis and Mycobacterium avium subsp silvaticum in long term cultures from Crohn's disease and control tissues. Gut 1992;33:1209-13.

26. Murray A, Oliaro J, Schlup MM, Chadwick VS. Mycobacterium paratuberculosis and inflammatory bowel disease: Frequency distribution in serial colonoscopic biopsies using the polymerase chain reaction. Microbios 1995;83:217-28.

27. Collins MT, Lisby G, Moser C, Chicks D, Christensen S, Reichelderfer M, et al. Results of multiple diagnostic tests for Mycobacterium avium subsp. paratuberculosis in patients with inflammatory bowel disease and in controls. J Clin Microbiol 2000;38:4373-81.

28. Frank TS, Cook SM. Analysis of paraffin sections of Crohn's disease for Mycobacterium paratuberculosis using polymerase chain reaction. Mod Pathol 1996;9:32-5

29. Pierce ES. Where Are All the Mycobacterium avium Subspecies paratuberculosis in patients with Crohn's Disease? PLoS Pathog 2009;5:e1000234.

30. Juste RA, Elguezabal N, Garrido JM, Pavon A, Geijo MV, Sevilla I, et al. On the prevalence of $M$. avium subspecies paratuberculosis DNA in the blood of healthy individuals and patients with inflammatory bowel disease. PLoS One 2008;3:e2537.

31. Nikkari S, McLaughlin IJ, Bi W, Dodge DE, Relman DA. Does blood of healthy subjects contain bacterial ribosomal DNA? J Clin Microbiol 2001;39:1956-9.

32. Juste RA, Elguezabal N, Pavón A, Garrido JM, Geijo M, Sevilla I, et al.
Association between Mycobacterium avium subsp. paratuberculosis DNA in blood and cellular and humoral immune response in inflammatory bowel disease patients and controls. Int J Infect Dis 2009;13:247-54.

33. Krajden M. Bridging the gap between analytical and clinical validation. In: Lorincz AT, editor. Nucleic Acid Testing for Human Disease. Boca Raton, FL: Taylor and Francis; 2005.

34. Ogura Y, Bonen DK, Inohara N, Nicolae DL, Chen FF, Ramos R, et al. A frameshift mutation in NOD2 associated with susceptibility to Crohn's disease. Nature 2001;411:603-6.

35. Hugot JP, Chamaillard M, Zouali H, Lesage S, Cezard JP, Belaiche J, et al. Association of NOD2 leucine-rich repeat variants with susceptibility to Crohn's disease. Nature 2001;411:599-603.

36. Cosnes J. Tobacco and IBD: Relevance in the understanding of disease mechanisms and clinical practice. Best Pract Res Clin Gastroenterol 2004;18:481-96.

37. Richter E, Greinert U, Kirsten D, Rüsch-Gerdes S, Schlüter C, Duchrow M, et al. Assessment of mycobacterial DNA in cells and tissues of mycobacterial and sarcoid lesions. Am J Respir Crit Care Med 1996;153:375-80.

38. Sechi LA, Paccagnini D, Salza S, Pacifico A, Ahmed N, Zanetti S. Mycobacterium avium subspecies paratuberculosis bacteremia in type 1 diabetes mellitus: An infectious trigger? Clin Infect Dis 2008;46:148-9.

39. Greenstein RJ, Su L, Juste RA, Brown ST. On the action of cyclosporine A, rapamycin and tacrolimus on $M$. avium including subspecies paratuberculosis. PLoS One 2008;3:e2496.

40. Runyon EH. Ten mycobacterial pathogens. Tubercle 1974;55:235-40.

41. Collins DM, Gabric DM, de Lisle GW. Identification of two groups of Mycobacterium paratuberculosis strains by restriction endonuclease analysis and DNA hybridization. J Clin Microbiol 1990;28:1591-6.

42. Harris NB, Barletta RG. Mycobacterium avium subsp. paratuberculosis in Veterinary Medicine. Clin Microbiol Rev 2001;14:489-512.

43. Roiz MP, Palenque E, Guerrero C, Garcia MJ. Use of restriction fragment length polymorphism as a genetic marker for typing Mycobacterium avium strains. J Clin Microbiol 1995;33:1389-91.

44. Whittington R, Marsh I, Choy E, Cousins D. Polymorphisms in IS1311, an insertion sequence common to Mycobacterium avium and $M$. avium subsp. paratuberculosis, can be used to distinguish between and within these species. Mol Cell Probes 1998;12:349-58.

45. Thorel MF, Drichevsky M, Le'vy-Fre'bault VV. Numerical taxonomy of mycobactin-dependent Mycobacteria, amended description of Mycobacterium avium, and description of Mycobacterium avium subsp. avium subsp. nov., Mycobacterium avium subsp. paratuberculosis subsp. nov., and Mycobacterium avium subsp. silvaticum subsp. nov. Int J Syst Bacteriol 1990;40:254-60.

46. World Health Organization. Pathogenic Mycobacteria in Water: A Guide to Public Health Consequences, Monitoring and Management. In: Pedley S, Bartram J, Rees G, Dufour A, Cotruvo J, editors. London, UK: IWA Publishing, 2004. p. 259.

47. Moreira AR, Paolicchi F, Morsella C, Zumarraga M, Cataldi A, Fabiana B, et al. Distribution of IS900 restriction fragment length polymorphism types among animal Mycobacterium avium subsp. paratuberculosis isolates from Argentina and Europe. Vet Microbiol 1999;70:251-9.

48. Singh S, Gopinath K. Non-tuberculous Mycobacteria in TB-endemic countries: Are we neglecting the danger? PLoS Negl Trop Dis, 2010; 4:e615.

How to cite this article: Singh S, Gopinath K. Mycobacterium avium subspecies paratuberculosis and crohn's regional ileitis: How strong is association?. J Lab Physicians 2011;3:69-74.

Source of Support: Nil. Conflict of Interest: None declared. 